\title{
Biodegradation of High Molecular Weight Polylactic Acid
}

\author{
Petr Stloukal $^{\mathrm{a}, \mathrm{b}}$, Marek Koutny ${ }^{\mathrm{a}, \mathrm{b}}$, Vladimir Sedlarik ${ }^{\mathrm{a}, \mathrm{c}}$ and Pavel Kucharczyk ${ }^{\mathrm{a}, \mathrm{c}}$ \\ ${ }^{a}$ Centre of Polymer Systems, Tomas Bata University in Zlin, nam. T.G.Masaryka 5555, 76001 Zlin, Czech Republic \\ ${ }^{b}$ Environmental Protection Engineering, Faculty of Technology, Tomas Bata University in Zlin, nam. T.G. Masaryka \\ 275, 76272 Zlin, Czech Republic \\ ${ }^{c}$ Polymer Centre, Faculty of Technology, Tomas Bata University in Zlin, \\ nam. T.G.Masaryka 275, 76272 Zlin, Czech Republic
}

\begin{abstract}
Polylactid acid seems to be an appropriate replacement of conventional non-biodegradable synthetic polymer primarily due to comparable mechanical, thermal and processing properties in its high molecular weight form. Biodegradation of high molecular PLA was studied in compost for various forms differing in their specific surface area. The material proved its good biodegradability under composting conditions and all investigated forms showed to be acceptable for industrial composting. Despite expectations, no significant differences in resulting mineralizations were observed for fiber, film and powder sample forms with different specific surface areas. The clearly faster biodegradation was detected only for the thin coating on porous material with high specific surface area.
\end{abstract}

Keywords: biodegradation, polylactide acid, gas chromatography, specific surface

PACS: $82.35 . \mathrm{Pq}$

\section{INTRODUCTION}

During the last century, there was a gradual increase in utilization of synthetic polymers in many areas of human life. Their dominant status in some areas was reached mainly due to the ever-improving physical and chemical properties that have led to the improvement of their resistance thus prolongation of their lifetime. Along with the growing world production of these materials the omnipresence of the plastic litter has become a serious environmental problem, which arised many actions and strategies to prevent and solve it.

Promising solutions seems to be the use of biodegradable polymers that could be able to replace conventional synthetic polymers in many applications $[1,2]$. One of the particularly perspective materials belonging to this family of polymers are aliphatic polyesters such as polylactic acid (PLA) due to its low toxicity and biodegradability $[3,4]$. Previously, the applications of PLA were limited to the biomedical area because of its high cost and relatively low molecular weight [5]. Recently, new techniques which allow economical production of high molecular weight (MW) PLA (greater than 100,000 Da) with relatively good mechanical, thermal and processing properties have brought further expansion of PLA utilization [5,6]. Therefore nowadays, this material can be used in a wide spectrum of products including packaging materials, mulching films and bottles and for preparation of fibres for nonwovens, textiles and carpets [7]. One of the possibilities for the treatment of biodegradable polymer waste appears to be the industrial composting [8].

Biodegradation of PLA has been already studied in number of research work [9,10,11] However, the biodegradation of high MW PLA, which is most commonly used in many common products, was not studied extensively enough especially regarding to the decomposition of different forms of final products in compost conditions.

In the present study, biodegradation of one particular example of high MW PLA in compost was investigated and its acceptability in an industrial composting plant regarding the rate of decomposition evaluated. Since the rate of biodegradation can be greatly affected by the form of the sample, various forms of the sample with different specific surface areas were tested.

6th International Conference on Times of Polymers (TOP) and Composites
AIP Conf. Proc. 1459, 20-22 (2012); doi: 10.1063/1.4738385

(C) 2012 American Institute of Physics 978-0-7354-1061-9/\$30.00 


\title{
MATERIALS AND METHODS
}

\begin{abstract}
Materials
The polymer used throughout the study was high molecular polylactic acid (PLA, $\mathrm{M}_{\mathrm{w}}=160000 \mathrm{~g} \cdot \mathrm{mol}^{-1}$, $\left.M_{w} / M_{n}=1.9\right)$ in the form of fibres.
\end{abstract}

\section{Polymer Processing}

Original form of the polymer was processed to obtain three other forms of the polymer with different specific surface areas.

Powder. Chloroform solution of polymer $(12,5 \mathrm{mg} / \mathrm{ml})$ was added gradually into four volumes of ethanol and the mixture was vigorously stirred. Obtained precipitate was filtered out and dried on air. As a result the fine powder with the high specific surface was obtained.

Films. Films $100 \mu \mathrm{m}$ thick were prepared by compression moulding at $160^{\circ} \mathrm{C}$ from obtained precipitated powder.

Thin coating on inert surface. Calculated volume $(10 \mathrm{ml})$ of the chloroform solution of polymer powder (100 $\mathrm{mg} / \mathrm{ml}$ ) was applied on the surface of pre-weighed porous inert material (perlite, $5 \mathrm{~g}$ ) and stirred. Then the solvent was stripped out with air leaving the polymer coating on the surface of perlite.

\section{Biodegradation Experiment}

The biodegradation tests were performed in $500 \mathrm{ml}$ biometric flasks equipped with septa on stoppers. Inside flasks three components were weighed: polymer samples $(50 \mathrm{mg})$, mature compost ( $5 \mathrm{~g}$ of dry weight) and perlite $5 \mathrm{~g}$. Sample flasks were incubated at $58^{\circ} \mathrm{C}$ to establish composting conditions. Head space gas was sampled at appropriate intervals through the septum with a gastight syringe and then injected manually into a GC instrument (Agilent 7890). Sampling was operatively adapted to the actual $\mathrm{CO}_{2}$ production and $\mathrm{O}_{2}$ consumption. From the $\mathrm{CO}_{2}$ concentrations found, the percentages of mineralization with respect to the initial sample carbon content were calculated. The endogenous production of $\mathrm{CO}_{2}$ by compost in blank incubations was always subtracted to obtain values representing net sample mineralizations. Three parallel flasks were run for each sample form (original fibre, film, powder and thin coating), along with four blanks without sample and positive control flasks with microcrystalic cellulose.

\section{RESULTS}

High MW PLA was designed to be biodegradable material hence it should be readily decomposed in compost. As it was already mentioned PLA can be utilized as a material for the production of many various products including agriculture films, fibres in textile industries, powder for special applications. However, all these products differ considerably in their surface area, which influence the rate and course of biodegradation proceeding apparently as a surface erosion process $(12,13)$. In order to evaluate this phenomenon with high MW PLA, several sample forms: film and fibres with relatively low specific surface and two other forms of the polymer with higher specific surfaces, solvent precipitated powder and deposition of the polymer on high specific surface inert material (perlite) were tested.

The resulted biodegradation curves in compost experiment are presented in Figure 1. Despite the fact that sample in form of fibres had the longest induction phase, its biodegradation reached surprisingly the same mineralization (about $65 \%$ after more than 90 days of incubation) as the powder sample with significantly higher specific surface area. The film form with low specific surface, which had the identical induction phase and behaved initially almost equally as the powder, reached, after a slight retardation in the middle of the observed period about $60 \%$ of mineralization. Despite significant differences in specific surface areas, the resulting final mineralizations of these three forms were approximately the same.

The fastest biodegradation was observed with the polymer coating on the porous perlit material, where it reached almost $90 \%$ at the end of the incubation period and was comparable with the biodegradability of microcrystaline cellulose powder used as a reference material. This result can be explained by the high specific surface of porous perlit, where the polymer was deposited as a thin layer. 
Final values of biodegradation for all sample forms could be evaluated as adequate and acceptable for the industrial composting.

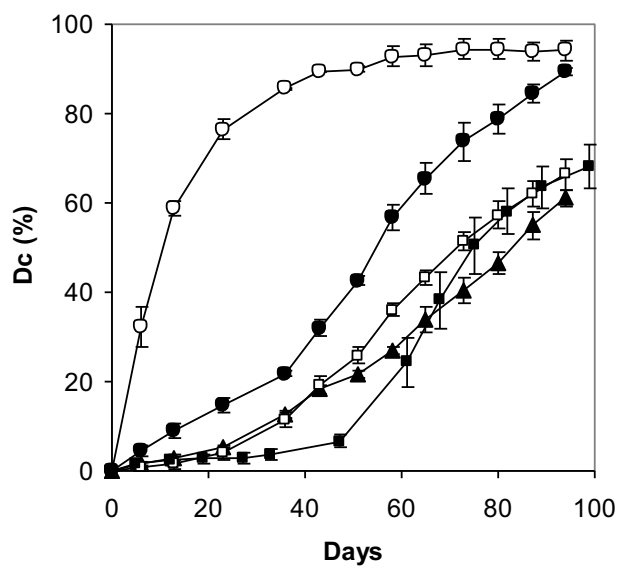

FIGURE 1. Biodegradation of different forms of the polymer in compost experiments. $\mathbf{\bullet}$, fibre; $\boldsymbol{\Delta}$ film $(100 \mu \mathrm{m}) \square$, powder; $\bullet$, thin coating; $\circ$, cellulose (reference compound). Error bars correspond to twice standard deviation $(n=3)$.

\section{CONCLUSION}

The biodegradation tests of high molecular PLA in various forms: fibres, powder, film and thin coating on inert material with different surface areas, in compost were performed. The material proved its good biodegradability under composting conditions and all investigated forms were evaluated as adequate and acceptable for the industrial composting. Contrary to the expectations, no significant differences in the final degree of mineralization were observed considering the various active surface areas of fiber, film and powder sample forms. However, the surface area have contributed to the different courses of biodegradation for the individual forms. Only for the thin coating on porous material with high specific surface area significantly faster biodegradation with no apparent initial lag-phase was observed.

\section{ACKNOWLEDGMENTS}

The study was made with co-founding by Internal Grant Agency of Tomas Bata University in Zlin (grant IGA/9/FT/11/D). The authors are also grateful to Operational Program Research and Development for Innovations co-funded by the European Regional Development Fund (ERDF) and national budget of Czech Republic, within the framework of project Centre of Polymer Systems (reg. number: CZ.1.05/2.1.00/03.0111). This work was also supported by the Grant Agency of Czech Republic grant GACR P108/10/0200.

\section{REFERENCES}

1. E. Rudnik, Compostable Polymer Materials. Amsterdam, Elsevier Science 2008 .

2. L. S. Naira and C. T. Laurencin, Prog. Polym. Sci. 32, 762-798 2007.

3. K. Fukushima, C. Abbate, D. Tabuani, M. Gennari and G. Camino, Polym Degrad Stabil 94, 1646-1655 2009.

4. K. Fukushima, D. Tabuani, C. Abbate, M. Arena and P. Rizzarelli, Eur Polym J 47, $139-1522011$.

5. K. Hamad, M. Kaseem and F. Deri, Polym Bull 65, 509-519 2010.

6. E. A. J. Al-Mulla, A. H. Suhail and S. A. Aowda, Ind Crop Prod 33, 23-29 2011.

7. L.-T. Lim, R. Auras and M. Rubino, Prog. Polym. Sci. 33, 820-852 2008.

8. A. Starnecker and M. Menner, Int Biodeter Biodegr 37, 85-92 1996.

9. K. Tomita, T. Nakajima, Y. Kikuchi and N. Miwa, Polym Degrad Stabil 84, 433-438 2004.

10. M. Kunioka, F. Ninomiya and M. Funabashi, Polym Degrad Stabil 91, 1919-1928 2006.

11. J.D. Badía, L. Santonja-Blasco, R. Moriana and A. Ribes-Greus, Polym Degrad Stabil 95, $2192-21992010$.

12. K. Herzog, R.-J. Muller and W.-D. Deckwer, Polym Degrad Stabil 88, 371-381 2005.

13. E. Rudnik and D. Briassoulis, Ind Crop Prod 33, 648-658 2011. 
Copyright of AIP Conference Proceedings is the property of American Institute of Physics and its content may not be copied or emailed to multiple sites or posted to a listserv without the copyright holder's express written permission. However, users may print, download, or email articles for individual use. 